\title{
Determining the Quality of Management and Structural Elements of the Epidemiology and Biostatistics Department in Tehran University of Medical Sciences
}

\author{
Fereshteh Farzianpour ${ }^{1 *}$, Kazem Mohammad ${ }^{2}$, Hossein Malekafzali², Saharnaz Nejat ${ }^{2}$ \\ ${ }^{1}$ Department of Health Management and Economics, School of Public Health, Tehran University of Medical \\ Sciences, Tehran, Iran \\ ${ }^{2}$ The Epidemiology and Biostatistics Department, School of Public Health, Tehran University of Medical \\ Sciences, Tehran, Iran \\ Email: ${ }^{*}$ farzianp@sina.tums.ac.ir, ${ }^{*}$ farzianp2@yahoo.com, Mohamadk@tums.ac.ir, malekafzali@tums.ac.ir, \\ nejatsan@tums.ac.ir
}

Received 6 September 2014; revised 2 October 2014; accepted 27 October 2014

Copyright (C) 2014 by authors and Scientific Research Publishing Inc.

This work is licensed under the Creative Commons Attribution International License (CC BY).

http://creativecommons.org/licenses/by/4.0/

c) (i) Open Access

\begin{abstract}
Introduction: The system of quality in higher education requires a systematic evaluation of all of its different aspects. Different patterns of evaluation reveal the strengths and weaknesses of the programs and facilitate the informed decisions. Objectives: The objectives of the present research are as follows: 1) Determining the quality of the structural elements of the Epidemiology and Biostatistics Department; 2) Determining the strengths, weaknesses, opportunities and threats to improve the quality of activities in the department under research. Design: In this research, the efficiency of the department was studied based on the internal self-evaluation. For this purpose, pre-determined indices with relative modifications were used. This study was conducted with the collaboration of the head of the department, faculty members, all of the students (residents, Ph.D. and M.S. students) and the graduates. Through a pilot study the initial rates of the areas under research were first determined by the opinion poll carried out among all the faculty members, then through proper tests, unrelated data were identified and omitted and the final rates were extracted. Results: The mean of the areas under study was $59.8 \%$ of which the minimum $(37 \%)$ was related to the area of aims and objectives and the maximum $(72.6 \%)$ related to area of the graduates. Conclusions: The graduate domain is one of the key areas under study in the internal evaluation of this department which received a good score.
\end{abstract}

\section{Keywords}

Quality of Management, Evaluation, Academic Department, Epidemiology and Biostatistics, Tehran ${ }^{*}$ Corresponding author.

How to cite this paper: Farzianpour, F., et al. (2014) Determining the Quality of Management and Structural Elements of the Epidemiology and Biostatistics Department in Tehran University of Medical Sciences. Journal of Service Science and Management, 7, 430-439. http://dx.doi.org/10.4236/jssm.2014.76040 


\section{Introduction}

The issue of quality in higher education has attracted a lot of attention [1]. Quality improvement has earned competitive advantages for organizations like higher education which attracted a lot of interested researchers to this area [2]. The system of quality in higher education requires a systematic evaluation of all of its different aspects. Different patterns of evaluation reveal the strengths and weaknesses of the programs and facilitate the informed decisions [3]. The educational activities of each country can be considered as an investment by one generation for the other. The main purpose of this investment is human development. In this regard, the evaluation of educational organizations, programs, staff and their services can have an effective role in improving the quality of education [4].

Martin believes that establishing a system of process evaluation in institutions and their programs is considered as a routine. That's why various methods of evaluation for accurate assessment of performance in higher education were developed [3]-[5]. Regardless of rules and regulations related to performance evaluation in countries and the limitations set for it, the necessity of the assessment of performance in countries, the manager's actions and decisions and the performance of institutions seems obvious. In situations where governments are faced with the increasing economic and social demands of people because of deficient availability, meeting demand and achieving goals and objectives for development , and making balance between demand and community resource require a comprehensive and ongoing evaluation and monitoring from which the higher education is not an exception [3] [6].

Regarding the significance of the issue, it is worth mentioning that the Islamic Republic of Iran Constitution emphasized on utilizing sciences and technology, and also training experts based on the needs for the development and improvement of the country's economy [7]. Also in the Code of the fourth economic, social, and cultural development plan, Article 49, the ongoing evaluation of universities, higher education centers, and governmental and private research centers by the ministries of science, research and technology, and health with the collaboration of scientific institutes is emphasized [8]. In this regard the accrediting council of higher education has recognized a system of accreditation as having the following stage [9]:

1) Internal evaluation: The plan and/or the report on the institute's performance are compiled with the contribution of the members.

2) Peer review: The self-evaluation report is reviewed by the faculty members and their peers in the same profession and their comments and suggestions will be released.

3) Site visit: An outside organization or agent sends the visiting team. The self evaluation report of the institute is the main source for the visiting team.

4) Judgment by accrediting organization: The intended plan of an organization or an institute is judged by the agents or the boards of the same institute or organization. This judgment is done based on three levels of: not accepted, conditional accrediting and accrediting.

5) Ongoing external review: Institution or plans are reviewed continuously within the range of 5 to 10 years and in some cases even less. It should be mentioned that the internal self evaluation report is reviewed just as before.

Considering the fact that there are controversies over the stages of accreditation and that there has been a thorough review in the related literature, one can infer the consensus and strong emphasis on internal and external evaluation from most of the texts in literature [9]-[19], while an increasing number of universities in the world have accepted the self evaluation method as their first step [12].

According to Lacino et al. (2004), international evaluation is the process of systematic gathering of data, asking question from and interviewing with the students, graduates and professors which leads to the self-evaluation report [13].

In internal evaluation, the aim is that those involved in planning should obtain more information on the objectives, and the issue concerning their achievements, then evaluate the ways to meet those objectives in order to improve the quality in future [1]. This type of evaluation will help the authorities to know how far they are from the desired situation and what plans they should consider in order to achieve the objectives and improve the 
quality [14].

According to what was mentioned above, we can conclude that for the ongoing improvement in the system of universities, establishing an efficient system of evaluation which both improves and promotes the scientific quality considering the improvement of the entire system of universities is required based on the needs and specificities of the system. The results of the pervious experiences on evaluation approaches have shown that internal evaluation for this purpose is desirable [15]. Furthermore, in order for the government's fourth development plan to be realized, internal evaluation is considered as the first step.

The evaluation and accreditation plan of the universities of medical sciences, have been approved in the government's third five year development plan of Iran. In this regard, both the Ministry of Health and Higher Education's priorities have been the objective oriented and the internal evaluation. Since 1996 the internal evaluation has started based on the objectives and in 2000 the external evaluation has been conducted in some of the universities of medical sciences [15]. Concerning what has just been mentioned, the internal evaluation in the Epidemiology and Biostatistics Department has started as an approved plan by TUMS Development Center in order to reveal the strengths and weaknesses, also threats and opportunities in addition to evaluating the quality [15].

\section{Material and Method}

This research is a descriptive, cross sectional and applied type of study. In order to gather the data, texts, dissertations, research plans, journals, documents and more important the internet were studied. The instruments used were note cards and questionnaires. The efficiency of the department was studied based on the internal selfevaluation. For this purpose, pre-determined indices with relative modifications were used.

This study was conducted with the collaboration of the head of the department, faculty members, all of the students (residents, Ph.D. and M.S. students) and the graduates. Through a pilot study the initial rates of the areas under research were first determined by the opinion poll carried out among all the faculty members, then through proper tests, unrelated data were identified and omitted and the final rates were extracted. In this evaluation 9 areas of 1) aims and objectives 2) organizational and management structure 3) faculty members 4) students 5) teaching and learning process 6) educational courses and curriculum 7) graduates 8) research and educational facilities and equipment and 9) research were studied using 61 criteria and 172 indicators. Five-point Likert Scale was used for the responses in the questionnaire $(<50 \%=$ undesirable, $50 \%-75 \%=$ rather desirable, $76 \%-100 \%$ completely desirable). Finally the data were analyzed using descriptive statistics indices and the assessment software of the Educational Development Center of TUMS. The instruments used in this method included assessment software, interview, observation and self-prepared questionnaire which consisted of 7 questionnaires and 2 check lists.

The questionnaires were prepared separately for the subjects including the evaluation committee, head of the department, the faculty members, students and the graduates. TUMS Development Center and the Ministries of Health and Education have confirmed the reliability and validity of the items in the questionnaire performed by internal evaluation software.

\section{Research Findings}

The findings (Table 1 and Figure 1, Figure 2) show that the desirability of the areas under study were as follows:

As shown in Box 1, Box 2 educational evaluation council on educational group of Epidemiology and Biostatistics was developed educational strategies based on special objectives and educational indicators based on criteria. Average results from educational evaluation at educational group were represented at (Table 1 and Figure 1, Figure 2). Strengths and weaknesses, opportunities and threats educational were analyzed on the basis of SWOTs pattern at the educational group (Box 3).

Research findings regarding each area in the Epidemiology and Biostatistics Department are as follows:

Aim and objectives: Considering the fact that the aims and objectives were recently set, the criterion related to the set objectives showed undesirable result. The generalizability and clarity of the objectives were relatively desirable. Considering the fact that the aims and objectives were set with the contribution of the members of the department with no official notification from the college, university or the Ministry, the criteria related to the involvement and contribution of the members in setting and clarifying the objectives (educational, research and 
Table 1. The degree and continuum of desirability of factors which were evaluated in department of epidemiology and biostatistics, School of Public Health, Tehran University of Medical Science.

\begin{tabular}{lcc}
\hline \multicolumn{1}{c}{ Evaluated factors } & Degree of desirability & Desirability continuum \\
\hline 1. Aims and objectives & $1.85(37 \%)$ & Undesirable \\
2. Organizational and management structure & $3.2(64 \%)$ & Rather desirable \\
3. Faculty members & $3.35(67 \%)$ & Rather desirable \\
4. Students & $2.72(54.4 \%)$ & Rather desirable \\
5. Teaching and learning process & $3.2(66.4 \%)$ & Rather desirable \\
6. Educational courses and curriculum & $3.38(67.6 \%)$ & Rather desirable \\
7. Graduates & $3.62(72.6 \%)$ & Rather desirable \\
8. Research and educational facilities and equipments & $3.02(60.4 \%)$ & Rather desirable \\
9. Research & $2.64(52.8 \%)$ & Rather desirable \\
\hline
\end{tabular}

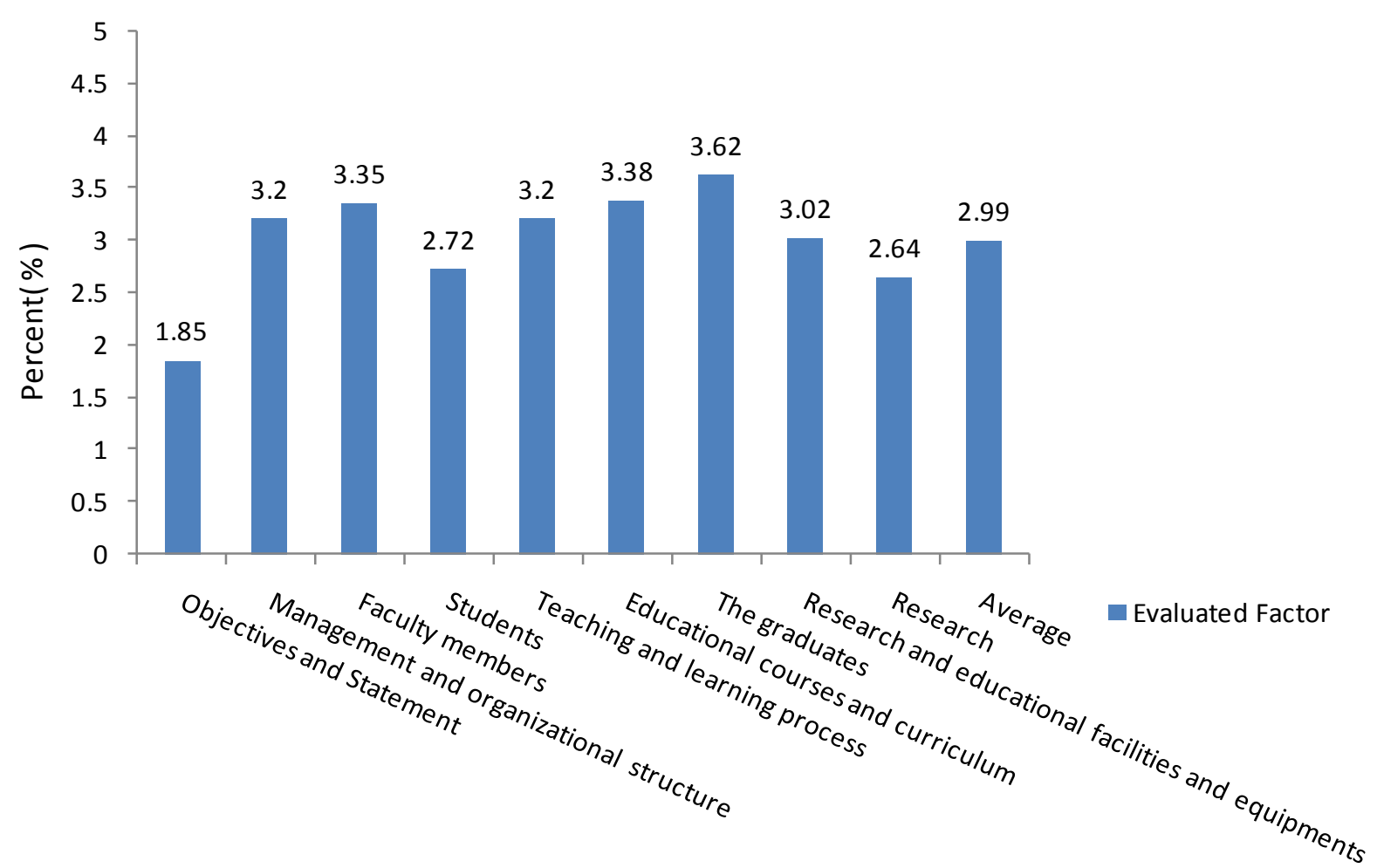

Figure 1. The desirability rate of the variables under evaluation based on Likert scale with total mean in the epidemiology and statistics departments, faculty of health in TUMS.

providing professional services) and the department's independence in setting and analyzing the objectives (educational, research and providing professional services) were desirable to some extent. Eventually, the findings show undesirable results for the achievement of the objectives. As a whole, the desirability of this factor was 37\%. Thus it is suggested the following measures be taken:

1) Clarification of the objectives set by the department;

2) Developing methods to modify the objectives and aims of the department considering the timing and the scientific situation;

3) Setting the objectives of the department based on a time table;

4) Considering the students' comments in developing the objectives of the department; 


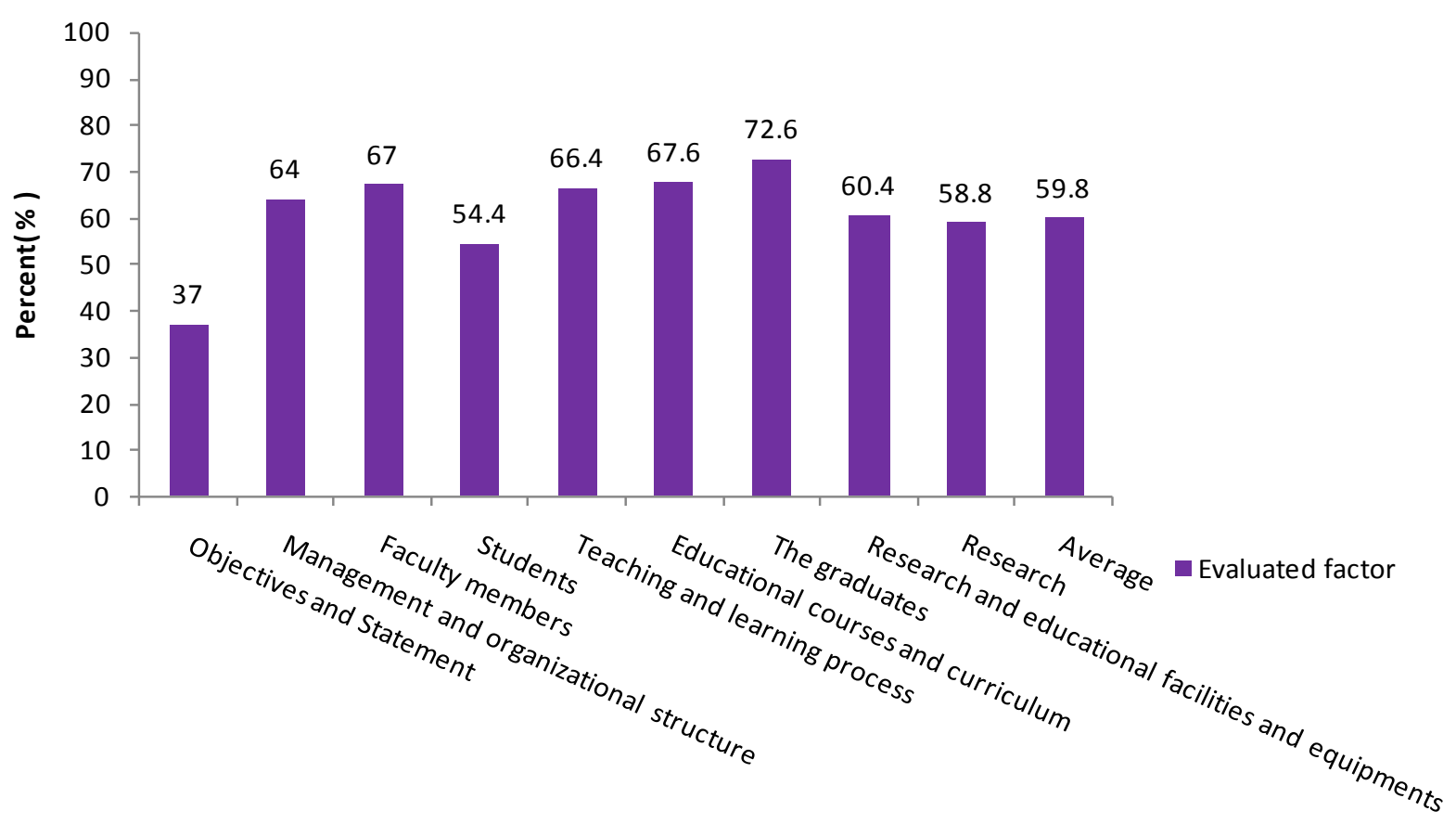

Figure 2. The desirability percentage of the areas under evaluation with total mean in the epidemiology and statistics departments, faculty of health in TUMS.

\section{Box 1. Educational strategies based on special objectives.}

\section{Special objectives}

Educational strategies

1) Improving and promotion of quality level and remedial hygienic research and educational program development conforming to society needs at university level.

2) Increasing the number of scientific board members and specialists in educational groups.

3) Knowledge development and achieving modern technologies.

4) Training efficient human resources at remedial hygienic research and educational courses.

5) Promotion of scientific board members, facilities, equipment conditions and educational resources in laboratories and so on in this purpose, strategies were developed for above mentioned special objectives.
1) Internal evaluation about educational programs quality.

2) Present permanent system reviews in order to performance of desirable internal evaluation.

3) Developing scientific relations with other universities and domestic and foreign authorized centers.

4) Promotion of short time educational courses qualitatively.

5) Promotion of remedial-hygienic research and educational materials and conditions qualitatively.

\section{Box 2. Indicators based on criteria.}

\begin{tabular}{|c|c|}
\hline Criteria & indicators \\
\hline Management & $\begin{array}{l}\text { Management organizational structure, remedial research, service and educational performance function } \\
\text { description, internal and external activities of members planning, management authorities. }\end{array}$ \\
\hline Scientific board & $\begin{array}{l}\text { Scientific board distribution, operational, remedial, hygienic research and educational activity information } \\
\text { and experience. }\end{array}$ \\
\hline Learners & Educational improving. \\
\hline Learning teaching process & $\begin{array}{l}\text { Applying educational technology by scientific board, educational improving, teaching methods } \\
\text { and graduates. }\end{array}$ \\
\hline $\begin{array}{l}\text { Educational courses } \\
\text { and curriculum }\end{array}$ & $\begin{array}{l}\text { Educational courses quality, conforming courses to objectives, group courses content, conforming courses } \\
\text { to mission, objectives, facilities and program evaluation. }\end{array}$ \\
\hline Graduates & $\begin{array}{l}\text { Capability, identification, relation between learners and their educational group after completing education, } \\
\text { occupational future (destination) keeping education, management and planning service receivers' comments } \\
\text { about learners occupation capabilities. }\end{array}$ \\
\hline Equipment & $\begin{array}{l}\text { Service remedial hygienic research and educational resources. } \\
\text { Space, facilities, laboratory, library, computer, visual and audio. }\end{array}$ \\
\hline Research & $\begin{array}{l}\text { Research activities, study opportunities research programs compiling, group, gathering, text magazine } \\
\text { research plans... }\end{array}$ \\
\hline Satisfaction & $\begin{array}{l}\text { Management, scientific board and learners satisfaction with all educational operational remedial hygienic } \\
\text { and research aspects. }\end{array}$ \\
\hline
\end{tabular}


Box 3. SWOTs at educational group.

S Management \& Organizing, Scientific board members, experienced and
powerful experts, Students, manpower curriculum development and graduates
$\begin{aligned} & \text { O Health Care, research and educational validity of university and } \\ & \text { foreign students }\end{aligned}$ $\begin{aligned} & \begin{array}{l}\text { W Scientific board welfare, modern Technology, spaces } \\ \text { of educational, research and health care equipment }\end{array} \\ & \text { T Powerful Scientific board retirement }\end{aligned}$

5) Examining the ways to achieving the objectives and implementing methods for periodical assessment of the achievements.

Management and organizational structure: The findings show that the development plan of the department and the faculty concerning the short term, long term, and the middle term plans, offering new courses of study, and the faculty's satisfaction from the plans and the available documents, are at desirable level. Furthermore, the specific planning and the assessment of the activities of the department, in spite of the unavailability of the documents, and reports and absence of systematized planning and evaluation of the activities of the department, was at desirable level. Of course, the faculty members showed their satisfaction from the consistency in planning. The interdepartmental activities with the other faculties and departments were at satisfactory level. The criteria regarding the faculty's contribution in planning the activities of the department and their satisfaction, also the systematized method of evaluation were at desirable level. The head of the department's policies, characteristics, obligations, responsibilities, and authorities were also desirable. However, the coordination between the department's planning and the college and the university, besides the proportion of the manpower and the facilities of the department to its planning was relatively desirable. In addition, the meeting schedule of the department and the faculty members' attendance was absolutely desirable and the bylaws of the department and their execution were satisfactory. On the whole, the desirability of this area was reported as $64 \%$. Thus considering the following points is required:

1) Setting the required plans for the development of the department and the preparation of appropriate timetable with the contribution of the faculty members and their continuing assessment;

2) Preparing specific by laws regarding the routines of the department;

3) Setting timetables regarding the development of human resources of the department;

4) Providing the facilities required for the assessment of the achievement rate of the objectives, performance of the department, and the annual reports;

5) Analyzing the needs of the manpower and the body resources of the department, and the necessary follow ups in meeting them.

Faculty members: The findings show that the composition and distribution of the faculty members are satisfactory and their educational activities and their documentation are completely desirable. Also, the faculty members' authorities and limitations in decision makings of the department were satisfactory and their presence in the department to counsel the students to was absolutely desirable. The faculty member's satisfaction from the department and its activities was absolutely desirable, and sharing of the experiences among the members was satisfactory. The faculty members showed their complete satisfaction towards the conveniences and the grants offered to them. Finally, the faculty members' knowledge of the latest findings in their own field of study and their relationships with the students and the colleagues were satisfactory. On the whole, the desirability of this area was reported as $64 \%$. For improving this factor, the followings are suggested:

1) Providing the facilities and conveniences for boosting the educational and research activities;

2) Setting plans for taking courses and dissertations and for the teaching hours of the faculty members and their other educational activities;

3) Planning for the preparation of the texts and the lesson plans by the faculty members.

Students: In this area the criteria related to the students' admission, the relationships between the students and the faculty members, the students' comments on the programs and activities of the department, their awareness of the objectives of the department, and the proportion of the number of students to the department's resources were relatively satisfactory. The educational achievements of the students of the department were satisfactory. Also, the students' role in planning the activities of the department and their knowledge of their own rights and obligations were to some extent satisfactory. On the whole, the desirability of this area was reported as $54.4 \%$. The following suggestions for improving the current situation are offered:

1) Providing a situation for increasing the authority of the department in admitting the PhD students and determining the general policies of students' admission; 
2) Informing students when entering the university and during their studies and benefiting from their comments;

3) Implementing clear criteria for monitoring the students' educational progress and providing them with proper feedbacks.

Teaching and learning process: The criteria related to the faculty members' teaching methodologies and the assessment of the students' learning were relatively desirable. The rate of the faculty members' use of technology in their teaching was desirable. However, the feedback to the students on their learning achievements and the makeup programs and the pre requisite courses for improving the students' learning were unsatisfactory. On the whole, the relative desirability showed 66.4\%. Thus, in order to improve teaching, learning, using teaching aids, make up and pre requisite courses, assessment and the feedbacks on the results of assessment of the students' achievements in education, the followings are suggested:

1) Holding workshops for the faculty members to share their ideas and experiences and also to advance their knowledge in implementing new teaching methodologies;

2) Appropriate planning to improve the quality of using information technology and teaching aides in the teaching process;

3) Holding meetings between the faculty members and the students and providing them with feedbacks;

4) Designing make up and pre requisite courses for the students based on their educational backgrounds and their needs.

Educational courses and curriculum: The educational level and the different disciplines of the department, conformity of the courses with aims and objectives, conformity of the courses with the facilities and the resources, and the departments' offering courses based on the principles of curriculum design, were reported as desirable. However, the comments of the members of the department (the head, the faculty members, and the students) on the quality of the courses, also the assessment of the course materials were relatively desirable. On whole, the desirability was reported as $67.6 \%$. In this regard, the followings are worth considering:

1) Systematic planning and evaluation of courses, programs and the course materials, also considering the students' comments and ideas;

2) Improving the appropriateness and variety of the subjects and the quality of the courses through ongoing evaluation, although the results show that conformity of the courses with the facilities, resources and the objectives of the department and the composition of the subjects were desirable.

The graduates: The competence, attitudes, and the cognitive abilities of the graduates of the department, also the contacts of the graduates with the department after graduating from the university were relatively desirable. The scientific works of the graduates were also desirable. In addition to that, the graduates' comments on the management of the curriculum of the department and their careers were desirable. On the whole, the desirability was $72.6 \%$. For improving the relationships of the graduates with the department and promoting the scientific activities, the followings are suggested:

1) Holding educational workshops for residents in order to enable them in compiling books and scientific journals;

2) Holding annual gatherings and calling on the graduates to improve the relationship and also to be informed about their careers.

Research and educational facilities and equipments: The criteria related to the space allocated for the office and education, library and information system, computer facilities and services, workshops and the labs of the department, and teaching devices were satisfactory and research facilities and equipments were relatively desirable. On the whole, the desirability level was $60.4 \%$. Although the findings related to this area was desirable, the followings are suggested for improvements:

1) Providing technologically advanced equipments for the physical extension of the department in the college;

2) Providing specialized texts for the department and their copies for the library;

3) Assigning a technician permanently for the research and educational advanced technologies for better administration and more efficiency;

4) Providing teaching aids for holding seminars and journal clubs in the department using the department funds or with the faculty's contribution from the conducted projects.

Research: Setting the research programs of the department and planning for research, financial resources of research, sabbaticals of the faculty members, and also the seminars and gatherings held by the department were desirable to some extent. The scientific and research activities and findings of the faculty members and the stu- 
dents were relatively desirable but the research contracts were desirable. On the whole, the area showed relative desirability (52.8\%). For this reason, the following suggestions are offered for improving the situation:

1) Planning and assigning the facilities required for compiling and translation of books by individuals or groups by the department;

2) Providing opportunities for the faculty members in seminars inside and outside the country;

3) Setting and implementing documented plans on budgeting research expenses;

4) Investigating the reasons for declining the sabbaticals by the faculty members and taking the necessary measures to improve it;

5) Considering the importance of research, assigning a committee to investigate the causes and the necessary strategies to improve the research area.

The above findings show that the evaluation of the department on the areas of goals, objectives, teaching and learning process, and research is lower than the other areas. However, studying the areas, criteria, and the indicators, also determining the strengths and weaknesses and the recommendations, are worth contemplating. Considering these recommendations by the Evaluation Committee will lead to the increase in the benefits and the improvement of the quality of the department.

\section{Discussions}

The internal evaluation is potentially a valuable process [11] and there is a positive attitude towards it in education and research in clinical affairs [16]. Researchers conducted in this area are as follows:

Farzianpour et al. in educational evaluation of 15 educational departments of clinical and basic sciences in TUMS stated that with internal evaluation an attempt can be made in eliminating the existing weaknesses and help setting an efficient educational system [17]. Yousefi et al. in the internal evaluation of anatomy department in Semnan University of Medical Sciences, has emphasized on improving the strengths and continuing the assessment [18]. Yarmohammadian and Kalbasi, after the internal evaluation of the educational departments of the management and medical information science of Isfahan University of Medical Sciences have stressed on the importance of being in contact with the students in improving the quality of education and research [19]. The researchers after doing internal evaluation of the child nursing education department of Semnan University of Medical Sciences have claimed that the findings were desirable, but found the revision and changes necessary [20]. Rafiee et al. after the internal evaluation of the internal surgery nursing department of Rafsanjan University of Medical Sciences expected earning higher scores in later evaluations because of the correction of undesirable indicators [21]. In 2008 findings, the internal evaluation was reported to be a standard method for accreditation in universities [22]. Dehghanipudeh et al. claimed that the internal evaluation is the first step in university accreditation and an attempt in controlling and improving the quality of education [23]. Yamani et al. suggested that the internal evaluation is a step in improving the quality of educational programs in Isfahan University of Medical Sciences [24]. Farzianpour et al., in TUMS, recommended that the internal evaluation based on the international standards especially the international standards of WFME is a method of accreditation of universities in the world [25]. Farzianpour et al., in TUMS, stated that the evaluation of different aspects of educational programs in the departments of clinical and basic sciences seems necessary because management equipped with observation and control devices for the educational programs is required [26]. Sedaee et al. reported that the faculty evaluation is basically the assessment of the merits. On the other hand, improving the quality of education, research, health and finally rehabilitation is one of the most important obligations of the authorities of the universities [27]. Parsa et al. in the internal evaluation of Nursing and Midwifery faculty found that the internal evaluation is the best indicator that shows the rate of achieving the goals and also analyzes the quality of educational activities and that by internal evaluation one can obtain logical results [28]. Rabbani et al., in the internal evaluation of the faculty of child diseases, stated that internal evaluation is a systematic process for gathering, analyzing and interpretation of data for studying the rate of achieving the goals [29]. Olyaee et al. in internal evaluation believed that appropriate assessment and research in education are considered as practical devices for catching up with the developments to improve the quality in educations, research and health [29].

In this research, the mean of the 9 areas results as $59.8 \%$, the minimum of which is related to the aims and objectives area as $37 \%$ and the maximum related to the graduates which was equal to $72.6 \%$. The department of Epidemiology and Statistics, with the scientific management, experienced faculty and competent students will be able to catch up with the international standard of WFME through timely organization and planning, and also 
play a dynamic and efficient role in higher education in the world. The novelty was in this research a self evaluation for quality improvement in system of teaching in Tehran University of Medical Sciences.

\section{Acknowledgements}

Full ethics approval for the research was given on 10 March 2010 by the Research Ethics Committee, Tehran University of Medical Sciences (REC TUMS Reference 10/03/2010). Ethical issues (Including plagiarism, Informed Consent, misconduct, data fabrication and/or falsification, double publication and/or submission, redundancy, etc.) have been completely observed by the authors.

\section{References}

[1] Farzianpour, F., Hosseini, S.H., Mirsepasi, A.B., Honary, H., Hosseini, S.S.H. and Hosseini, S. (2013) Internal Evaluation of the Department Environment Al Health Science and Engineering. American Journal of Applied Sciences, 10, 58-63.

[2] Askari, R., Farzianpour, F., Goudarzi, R., Safii, M. and Shojaei, S. (2014) Efficiency Evaluation of Hospitals Affiliated with Yazd University of Medical Sciences Using Quantitative Approach of Data Envelopment Analysis in the Year 2001 to 2011. Pensee Journal, 76, 416-425.

[3] Bazargan, A. (2001) Educational Evaluation: Concepts, Patterns, and Operational Process. SAMT Publication, Tehran, 114. (In Persian)

[4] The Office of Editing and Compiling Laws and Regulations (1980) The Constitution of Islamic Republic of Iran and Legal Bills Enacted by the Revolutionary Council of Islamic Republic of Iran. The Office of Editing and Compiling Laws and Regulations, Tehran, 11.

[5] The Office of Administrative, Financial, and Human Resource Affairs of Documentation Center (2004) The Code of the Fourth Economic, Social, and Cultural Development Plan of Islamic Republic of Iran 2005-2009. The Office of Administrative, Financial, and Human Resource Affairs of Documentation Center, Tehran, 74.

[6] Farzianpour, F., Emami, A.H., Davari-Tanha, F., Hosseini, S. and Farzanehnejad, A.R. (2010) Educational Programs' Quality Assessment Based Ongraduates’ Comments. Iranian Red Crescent Medical Journal, 12, 302-307.

[7] Farzianpour, F., Dargahi, H., Hosseini, S., Hosseini, S.S. and Hosseini, S. (2011) Program Evaluation of Health Care Management: Is It Adjusted for Students Needs? American Journal of Economics and Business Administration, 3, 420424. http://dx.doi.org/10.3844/ajebasp.2011.420.424

[8] Farzianpour, F., Dargahi, H., Eynolahi, N. and Aghababa, S. (2010) Internal Evaluation in Department of Health Care Management in Faculty of Allied Medical Sciences Tehran University of Medical Sciences. Health Information Management, 7, 353-360.

[9] Mohammadi, R., Fatabadi, J., Yadegarzadeh, Gh., Mirzamohammadi, M. and Parand, K. (2005) Evaluation of Quality in Higher Education: Concepts, Principles, Methods, Criteria. The Publication Center of the State Educational Assessment Organization, Tehran, 168.

[10] Sayari, M., Sayari, H. and Ebrahimi, H. (2006) External Evaluation and Accreditation in the System of the Higher Education. Mehr Sobhan Publication, 120. (In Persian)

[11] Farzianpour, F., Aghababa, S., Delgoshaei, B. and Haghgoo, M. (2011) Performance Evaluation a Teaching Hospital Affiliated to Tehran University of Medical Sciences Based on Baldrige Excellence Model. American Journal of Economics and Business Administration, 3, 272-276.

[12] Farzianpour, F., Askari, R., Hamedani, A.T., Khorshidi, G., Amirifar, S. and Hosseini, S. (2011) Accreditation of Emergency Department at a Teaching hospital in Tehran University of Medical Sciences in 2010. American Journal of Economics and Business Administration, 3, 498-505. http://dx.doi.org/10.3844/ajebasp.2011.498.505

[13] Farzianpour, F., Hosseini, S.H., Mortezagholi, S., Bamdad, K. (2014) Accreditation of Patient Family Education in the Teaching Hospitals of Tehran University of Medical Sciences from the Nurses View. Pensee Journal, 76, 182-193.

[14] Harden, R.M. (2000) Task-Based Learning: The Answer to Integration and Problem Based Learning in the Clinical Years. Medical Education, 34, 391-397. http://dx.doi.org/10.1046/j.1365-2923.2000.00698.x

[15] Farzianpour, F. and Bazargan, A. (1999) Evaluation of Clinical Education Departments of Tehran Hospitals. Tehran University Medical Journal, 57, 72-78.

[16] Farzianpour, F., Sedighi Gilani, M., Zeinalou, A. and Eshraghiyan, M. (2007) Educational Evaluation in 15 Departments of Clinical and Basic Sciences in TUMS. http://edu.tums.ac.ir

[17] Yousefi, B., Tabrizi Amjad, M.H., Taherian, A., Safari, M., Sameni, H.R., Aldaghi, M. and Haghighi, S. (2001-2002) The Internal Evaluation of the Anatomy Department of Semnan University of Medical Sciences. 
http://www.sid.ir

[18] Yarmohammadian, M.H. and Kalbasi, A. (2006) The Internal Evaluation of Departments in Medical Dissemination and Management Faculty in Isfahan University of Medical Sciences. The Iranian Journal of Education in Medical Sciences, 6, 125-134.

[19] Fakhre Movahedi, A. and Ahadi, F. (2003) The Internal Evaluation of the Child Nursing Department of Semnan University of Medical Sciences. The Scientific Journal of Semnan University of Medical Sciences, 5, 47-52.

[20] Rafiee, G.R., Khodadadizadeh, A., Kazemi, M., Shahbaninezadeh, M., Ravari, A., and Bakhshi, H. (2004) The Internal Evaluation of Internal Surgery Nursing Department in Rafsanjan University of Medical Sciences. The Scientific Journal of Semnan University of Medical Sciences, 5, 9-17.

[21] Hajiabadi, M.R., Kalbasi, S. and Khazaiee, Z. (2008) The Internal Evaluation of Standard Method for Educational Accreditation in General Medicine. The International Congress of the Implementation of the International Standards of the World Federation of Medical Education in General Medicine Education Program, The Ministry of Health and Medical Education, Office of Education, 59-60. (In Persian) http://www.Ime-cong.ir

[22] Dehghani, P., Yamani, N., Dadman, M., et al. (2008) The Internal Evaluation of Anesthesiology Department of the School of Medicine in Isfahan University of Medical Sciences in 2007. The International Congress of the Implementation of the International Standards of the World Federation of Medical Education in General Medicine Education Program, The Ministry of Health and Medical Education, Office of Education, November 2008, 65-66.

[23] Yamani, N., Changiz, T., Mosavi, S.A., et al. (2008) International Evaluation as a Step to Improve the Quality of Educational Programs in Isfahan University of Medical Sciences. The International Congress of the Implementation of the International Standards at the World Federation of Medical Education in General Medical Education Program, The Ministry of Health and Medical Education, Office of education, November 2008, 161-162.

[24] Farzianpour, F., Emami, A.H., Kavosi, Z., et al. (2008) TUMS Accreditation Using the International Standard of WFME. The International Congress of the Implementation of the International Standards at the World Federation of Medical Education in General Medicine Education Program, The Ministry of Health and Medical Education, Office of Education, November 2008, 165-166.

[25] Farzianpour, F., Emami, A.H. and Eshraghiyan, M.R. (2007) The Evaluation of Educational Department Plan of Clinical and Basic Sciences in TUMS. Research Quarterly in Educational Systems, 1, 46-48. (In Persian)

[26] Sedaee, M., Farzianpour, F., Mohammadkhani, G., et al. (2007) The Internal Evaluation of the Audiology Department in the Faculty of the Rehabilitation in TUMS. Iran Journal of Audiology, 16, 1-9.

[27] Parsa, Z., Salmani Barough, N., Monjamed, Z., et al. (2005) The Internal Evaluation in Nursing and Midwifery School of TUMS. Hayat Quarterly, 11, 71-78.

[28] Rabbani, A., Farzianpour, F., Zamani, G.R., et al. (2006) The Internal Evaluation in Child Disease Department of Medical School in TUMS. The Journal of Children Diseases in Iran, 16, 301-307.

[29] Olyaee, G.R., Hadian, M.R., Farzianpour, F., et al. (2007) The Internal Evaluation in Physiotherapy Department. The Rehabilitation School in TUMS. Journal of Modern Rehabilitation, 1, 19-24. 
Scientific Research Publishing (SCIRP) is one of the largest Open Access journal publishers. It is currently publishing more than 200 open access, online, peer-reviewed journals covering a wide range of academic disciplines. SCIRP serves the worldwide academic communities and contributes to the progress and application of science with its publication.

Other selected journals from SCIRP are listed as below. Submit your manuscript to us via either submit@scirp.org or Online Submission Portal.
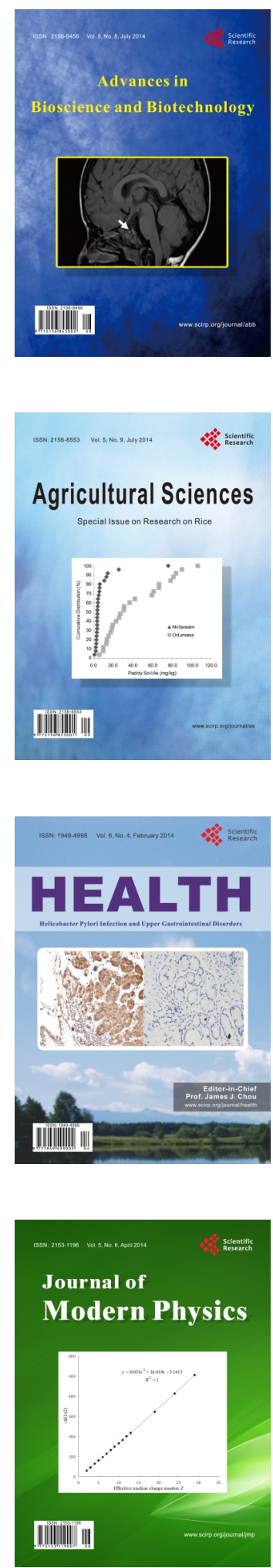
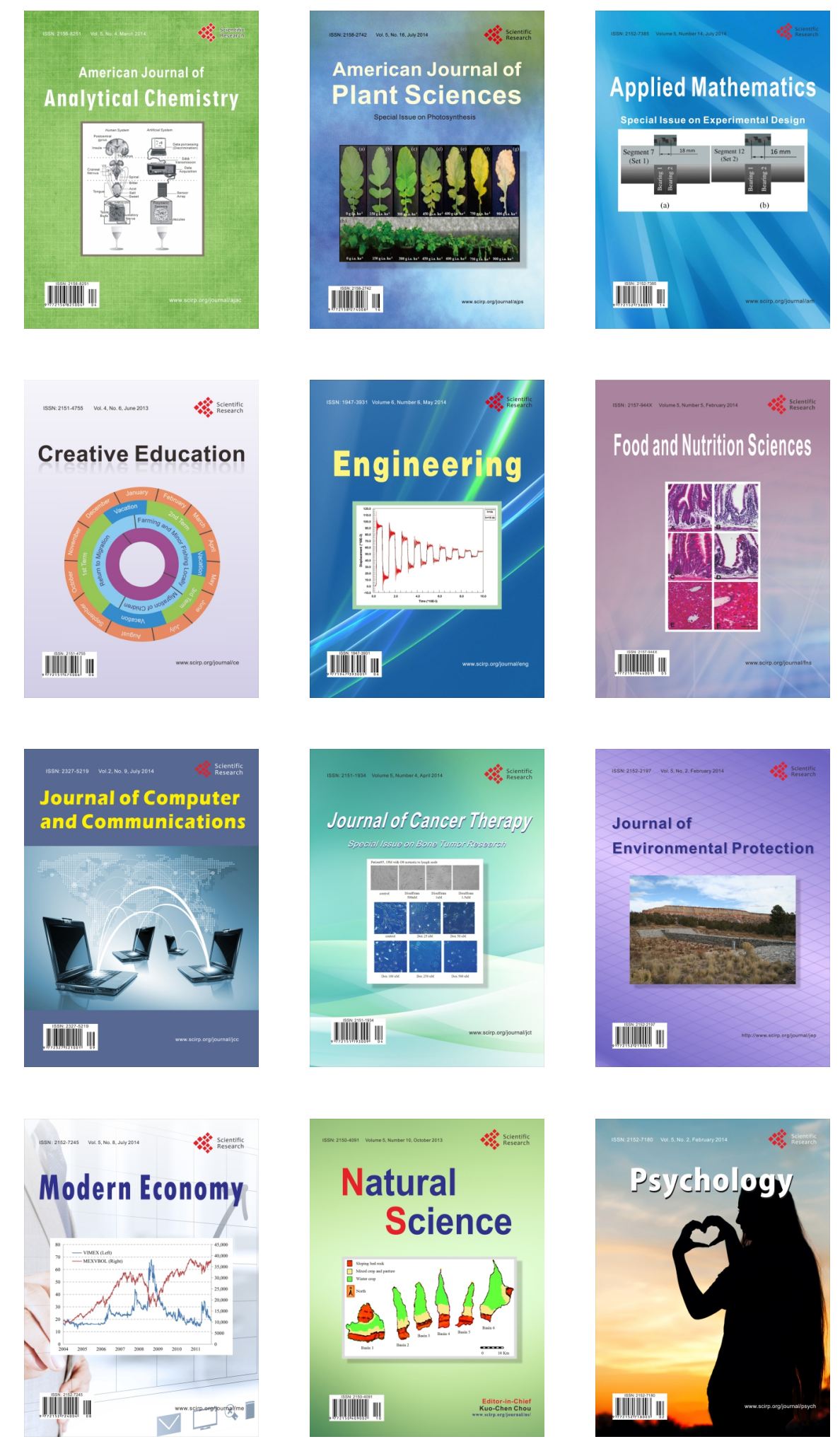